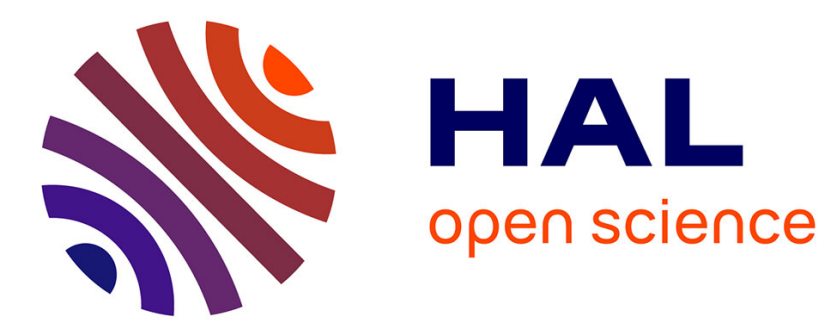

\title{
The acquisition of arithmetical concepts
}

Gérard Vergnaud

\section{To cite this version:}

Gérard Vergnaud. The acquisition of arithmetical concepts. Educational Studies in Mathematics, 1979, 10 (2), pp.263-274. 10.1007/BF00230990 . hal-03049803

\section{HAL Id: hal-03049803 https://hal.science/hal-03049803}

Submitted on 10 Dec 2020

HAL is a multi-disciplinary open access archive for the deposit and dissemination of scientific research documents, whether they are published or not. The documents may come from teaching and research institutions in France or abroad, or from public or private research centers.
L'archive ouverte pluridisciplinaire HAL, est destinée au dépôt et à la diffusion de documents scientifiques de niveau recherche, publiés ou non, émanant des établissements d'enseignement et de recherche français ou étrangers, des laboratoires publics ou privés. 


\section{THE ACQUISITION OF ARITHMETICAL CONCEPTS}

Arithmetic is usually considered a rather vulgar part of mathematics compared with geometry and algebra. Some historical research both in the history of education and in the history of mathematics would be necessary to understand why this is so. Probably the leap that the child is supposed to make from elementary arithmetic at the primary level to the noble mathematical concepts of equation, function, point, line and plane at the secondary level has something to do with this prejudice against arithmetic.

The current trend of modern mathematics has made the situation for arithmetic rather worse than it was before. Also the reaction against modern mathematics that has sprung up in the last few years is very often presented as a return to good, useful, commonsense arithmetic.

The title chosen for this paper: 'the acquisition of arithmetical concepts' is intended to portray a better cognitive status for arithmetic, instead of associating it with boring and out of date calculation, and to relate it to modern mathematics instead of opposing one to the other.

As a matter of fact arithmetic, even in its elementary aspects, deals with very important mathematical concepts. To establish the link between ordinary arithmetical situations and the relevant mathematical concepts is probably the most challenging question in mathematical education. This link is important for developing both an ability to solve ordinary arithmetical problems and a better understanding of some more sophisticated concepts.

It is well known that the ability for calculation of secondary-school pupils is not very good, but it would be misleading to think of these difficulties only in terms of 'calculating ability'. Most difficulties met by pupils are difficulties in the concepts involved, and not in the calculations. Of course, this does not mean that calculation of itself raises no problem.

It is this problem of conceptualization that some groups are trying to tackle in studying the complexity of different capacities and in organizing conditions which make possible the emergence of these capacities. Solving a problem by choosing the right calculation is a very strong criterion for the acquisition of concepts. Operational thinking in mathematics has a lot to gain in being tested and analysed through problem solving situations, because a concept that is not operational is not really a concept. Of course, a solving 
procedure is not a concept either. It must also be thought over, or explained, in terms of properties and relationslips.

But there is so little stress on physical and natural situations that psychologists feel the need (especially in France) to call mathematicians back to the relationship that mathematics has with reality. The concept of number would not even exist if man had not met problems of measurement; and the concepts of function and equation refer to very elementary aspects of the ordinary activity of the child in the world.

Summarizing this short epistemological introduction, I would say that teachers and psychologists must be firmly aware of two kinds of consideration:

- on the one hand: start from the analysis of situations implying quantities, transformations of quantities, and relationships between quantities; and test mathematical knowledge against problem-solving in such situations.

- on the other hand: make successive steps to abstract different sorts of mathematical objects and different sorts of symbolic representation of these objects.

When a pupil uses a certain procedure to solve a problem, he is using what I call a 'theorem in action' which is not yet a theorem. When a pupil is able to repeat verbally a theorcm, it is not necessarily a theorem in action. There is no operational thinking without the coordination of these two criteria.

Psychologists and psychologically-minded teachers can be very helpful in studying the problem of developmental complexity, because developmental complexity cannot be inferred directly from mathematical complexity. For instance, two independent axioms such as commutativity and inversion of additive transformations are not mastered at the same level by the child, because they do not refer to the same task in problem-solving and because the complexity of these tasks is not the same. Another example on which different researchers (Noelting, 1978; Hart, 1978; Karplus et al., 1977) have found very important results is proportion: different properties, almost equivalent for the mathematician, are not at all equivalent for the child.

But the problem of complexity should not be seen in too general terms. Of course it always refers to the complexity of concepts but, as a psychologist, I suggest a task-oriented, behaviour-oriented and symbolic-representationoriented analysis of complexity.

\section{COMPLEXITY OF TASKS}

The same concept can be involved in a variety of situations and tasks that do not need the same 'relational calculus'. By 'relational calculus' I mean the transformation and composition of relationships given in the situation. For 
instance the same relational calculus is not required to substract 6 from 24 in the three following situations.

(a) I had 24 francs and spent 6 francs. How much do I have now?

(b) My grand-mother has just given me 6 francs and I now have 24 francs. How much did I have before?

(c) I spent 24 francs this morning and my mother gave me some money in the afternoon. I now have six francs less than I had at breakfast. How much did my mother give me?

Of course, the analysis of tasks is still more useful when you have much numerical data, including non-relevant data, or when you must find intermediary results, or when you need some measurement or counting to complete your data. But as I cannot go into details in this paper and only want to suggest a few questions I will mention two important notions, which the mathematician usually ignores, and which must be reintroduced into our reference-frame if we want to analyse the relationships that the pupils take into account in arithmetical tasks. These notions are:

\subsection{Time}

Situations usually happen in time with a very obvious order-relationship: initial state, transformation, state, transformation, . . . final state. Especially for additive transformations (plus or minus something) it is necessary to keep time in mind when analysing the tasks.

\subsection{Dimension}

Numerical situations usually deal with quantities that are not pure numbers but magnitudes of various kinds. These magnitudes can be elementary magnitudes, or they can be products or quotients of elementary magnitudes. It is necessary to take these dimensions into account not only to analyse tasks but also to lead pupils to some important theories such as dimensional analysis, linear mapping and vector space theory.

One cannot make a proper classification of tasks by only referring to the notion of number. Numbers are undoubtedly central in mathematics but it is impossible to understand what difficulties children meet with numbers if you do not look at them as magnitudes of different sorts, transformations, or relationships.

Moreover there are specific obstacles which arise from the specific nature of the physical concepts involved. These obstacles must be studied too: the ratio of distance to time, the ratio of mass to volume raise more problems 
for children than the ratio of money to a quantity of sweets. The analysis of these specific problems is part of the analysis of tasks. So is the analysis of problems raised by the choice of numerical data in certain subsets of values: decimals, rationals, values under $1 \ldots$

All this brings us to the idea that it is hopeless to try to understand the acquisition of arithmetical concepts and to propose better conditions for the child to understand them if one does not make the effort to analyse the tasks through which these concepts are made meaningful and useful to the child. This analysis, if we want it to be systematic, must include many aspects: relational aspects, amount of data, subsets of chosen values, physical or other concepts that are involved. The possible tasks may appear as an unnecessarily wide variety and it may happen that some distinctions are useless when we know more about them. But, for the time being, because not enough mathematicians are aware of it, it seems more profitable to accept the variety of tasks as a richness and a source of new and interesting experimentations.

\section{COMPLEXITY OF BEHAVIOUR AND PROCEDURES}

For the same task, the same problem or the same situation, pupils will offer a variety of procedures. There is not only one way of getting the right answer, there is not only one wrong answer and there is not only one way of obtaining the same wrong answer. These different procedures, right or wrong, are not equivalent from a cognitive point of view.

More generally speaking, the behaviour of pupils in a new situation can be very different and the observation of that behaviour is very useful to comprehend what makes sense to them. I will only give two examples.

The first one refers to a rather restricted notion of procedure. In the very classical problem

given $a, b, c$, such that $b=f(a)$, find $x=f(c)$ when $f$ is a direct proportion (consumption of something in relation to time for instance)

one finds more than twenty different sorts of procedures that imply different ways of looking at the relationships in the task and different ways of dealing with them. Among the successful ones, there are differences which show different degrees of generality. The properties taken into account are not the same.

As concerns the unsuccessful procedures, it is possible to classify them into different subclasses which do not have the same meaning from a cognitive point of view. 
That example is very important because many calculation abilities rely upon it.

I will tum to a second example which does not refer to a strict meaning of procedure but rather to a wider notion of behaviour. If I take the metaphor of the rat in the maze, when no aim is given to him, and of the 'orientation responses' that he usually makes, I will say that very often, situations in the class-room are at first mazes to the pupils. It is most interesting to observe their 'orientation responses'. Of course there are all sorts of such responses but one can restrict oneself to some subsets of them. You can study for instance the way they tackle a new set of materials (blocks for instance) or a new situation including relationships and data which they have never met before. Our research group" is now studying the questions that pupils invent and find meaningful when they face data with no question. Of course some questions are stereotypes but it is interesting to observe the choice of questions, the formulation of them and the discussions about what is interesting or not, what is answerable or not.

I will conclude this part on procedures by saying that the study of the difficulty of tasks (of items in a test for instance) is undoubtedly the first priority. But it would be misleading to think of the problem of complexity only in terms of difficulty of tasks. The complexity of procedures and behaviour is also very important. The easiest way to tackle a difficult problem may be easier than a more sophisticated way of tackling a simpler one. Theorems in action, as seen through the analyses of procedures, are supposed to lead to explicit mathematical theorems. It is important to know which ones are more natural and which ones more complex. For instance the study of procedures may lead to the conclusion that it is better to state explicitly the homomorphic property of linear mapping

$$
f(\lambda x)=\lambda f(x)
$$

than state the more usual expression

$$
f(x)=a x
$$

but this also raises the problem of the complexity of representations.

* This group studies the acquisition and teaching of multiplicative structures on 11-15 year-old-pupils. It is sponsored by DGRST No. 76-7-1093. It comprises mathematicians (André Rouchier, Patrick Marthe et René Mètregiste) and psychologists (Graciela Ricco and myself). 


\section{COMPLEXITY OF REPRESENTATIONS}

It is well known that mathematicians use different sorts of representations according to the problem they have to solve or the theorem they have to prove. But this idea has not been systematically studied in education. The problem of representation is not at all simple, because there are at least two different meanings of the word.

(1) The most widely accepted one is 'symbolic representation' according to which different sorts of symbols stand for objects of different mathematical status: elements, operations, relationships, classes, functions . . . Of course there may be different sets of symbols referring to different (or to the same) sets of objects.

(2) The other important meaning of representation is 'thinking' (conceptual or preconceptual thinking) when no reference is made to any explicit system of symbols, even to ordinary verbal language. Representation is then that sort of thing that you can infer from the behaviour and explanations of a subject.

The linguistic distinction between 'signifier' ('signifiant' in French) and 'signified' ('signifie' in French) does refer to these two meanings of representation. But for the psychologist, the 'signified' should be analysed through all aspects of behaviour, and especially action in problem-solving and not only through the symbols by which the subject tries to represent things.

In simpler words, you can learn more about the meaning of subtraction for a child if you study the way he deals with problems that need the use of a subtraction than if you only study his use of words and signs referring to subtraction. For a psychologist, the 'signified' refers more to action and behaviour than to explicit symbolisation although both references should be taken into account and not be opposed to each other. Concepts and preconcepts are better analysed through the actual capacitics of pupils in problemsolving situations than through verbal definitions and theorems.

But this does not solve the problem of the role played by symbolic representations. As a matter of fact, mathematicians agree that symbolic representation is very important in mathematics: they spend a lot of time coming to an agreement on the best and canonical ways of designating and writing mathematical objects.

How can we transfer that problem into didactics?

My first point will be that we must try to make operational the problem of symbolic representation by finding tasks in which a symbolic representation helps pupils to solve the task. This is not so easy: most teachers know that pupils very often solve the problem first, and write its representation afterwards. We must try to find, for all levels of education, classes of problems and 
symbolic systems such that the former ones could not be easily solved without the help of the latter ones: classes of problems that could not be solved without being 'put into equation'. Of course I use the word 'equation' as a generic metaphor, because equations are not the only way of representing a problem. One of the aims of teaching should be, for all symbolic systems, the discovery of problems implying a variety of data and relationships that makes it necessary for the child to use a symbolic representation to make the right interpretation of relationships and the right choice of data.

If you test, against that criterion, the arithmetical equations that children are supposed to use at primary school, they are very seldom operational: not only because they come after the solution has been found, but also because they do not usually represent the relationships in the problem, but rather the operations the child has made to solve it. Venn-Euler circles, trees and arrow diagrams should be tested against the same criteria. It is probably the case that a system is efficient at certain levels and for certain classes of problems and not for other levels or for other problems.

I do not have many results, only some data on the use of arrow-diagrams in additive problems when a succession of states and transformations occurs. This data seems to show that pupils are better at using diagrams than equations at the end of primary school and beginning of secondary school. I also have some observations concerning the use of diagrams and tables for multiplicative problems.

My second point concerning the problem of symbolic representations is that it is sometimes better to differentiate between situations that are not the same for the child although they do come to the same numerical equation. For instance $a+x=b$ refers to many different classes of problems which are not at all equivalent for the child. So how can he find it natural to represent them by the same equation? Of course it is justifiable, at a certain level, to deal only with numbers and work on the general equation $a+x=b$, but that work can hardly be meaningful to the pupil if he is still trying to understand how $a+x=b$ can represent such different problems as addition of cardinals, additive or negative transformation of a state into a state, composition of transformations or transformation of a relationship.

The same sort of problem arises for $a x=b$.

So a symbolic system can be too abstract if different situations have the same representation in it. It may then be helpful for the pupil to use more

\footnotetext{
* This data has been collected by a group that studies the coordination of maths-teaching between primary and secondary schools. It is sponsored by the Ministry of Education, and is led by Paule Errecalde (INRP).
} 
differentiated systems for a while, and to prepare the introduction of the most abstract system by these intermediary steps. It is often good to use several symbolic systems at the same level and link one to another.

Here I will stop listing the problems which can be considered under the theme of complexity: tasks, procedures, representations. They all refer to the order relationship (total or partial order, genetic or not) in acquisition. I will turn now, very briefly, to an example that can illustrate the ideas which I have tried to develop.

Consider two problems A and B that concern primary school children:

A. John has played marbles with friends. In the morning he won 14 marbles. In the aftemoon he lost 31 of them. He has now 23 marbles. How many did he have before playing?

B. John has played marbles with friends. He had 14 marbles before he started. He played in the morning and in the afternoon. In the afternoon he lost 31 marbles. He has now 23 marbles. What happened in the morning?

And here are four systems representing these problems (there are others of course).

I

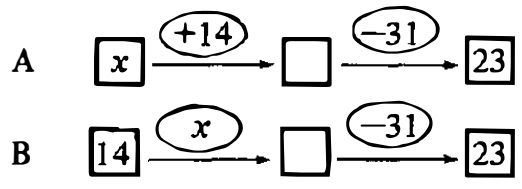

II
A $x+14-31=23$
B $\quad 14+x-31=23$
equivalent

III A or B

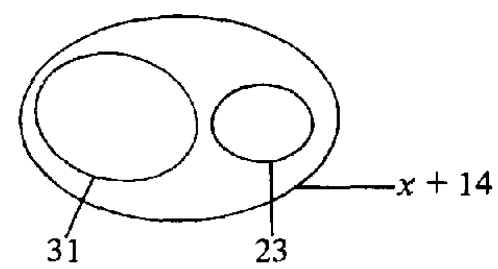

IV

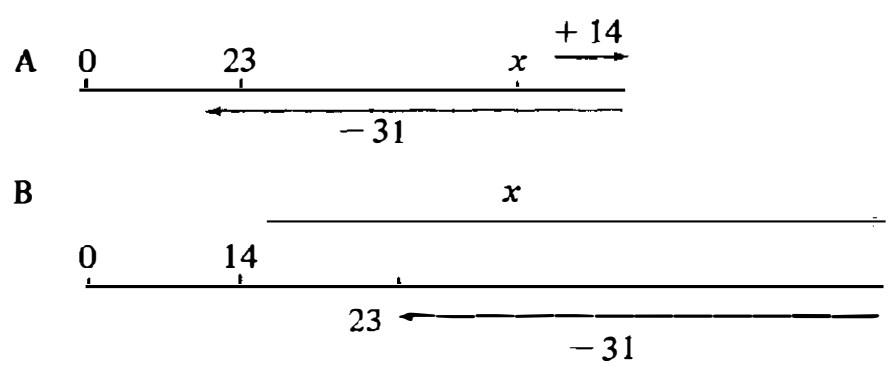


These four systems are not obviously useful.

System II for instance designates by the same $x$ a state (positive number) in $\mathbf{A}$ and a transformation (positive or negative number) in $\mathrm{B}$. The sign plus and minus do not have the same meaning either, as appears in the solution

$$
x=23+31-14
$$

sign minus means inversion of a positive transformation in $\mathbf{A}$ and subtraction of a natural number in $B$.

System III is not very natural in that case and needs some thinking to be used correctly, especially for B because one does not know the sign of $x$ ( $x$ would have a different sign if you had 74 instead of 14).

System I is obvious. This is not amazing because the example has been chosen on purpose. Of course there are situations for which system III or system II are obvious.

System IV is similar to system I as regards the difference between a state (position) and a transformation (move) but it is not very easy to use it, because the direction of moves should be known: this is not the case in B.

Let us turn now to the procedures: for example problem A can induce different procedures:

a

b

c

add 31 to 23 ; then subtract 14 subtract 14 from 31 ; then add this result to 23 make a hypothesis on $x$; apply +14 then -31 and change the hypothesis according to the gap between this result and 23 .

There are some other good procedures and many bad ones. But let us limit ourselves to $\mathrm{a}, \mathrm{b}$ and $\mathrm{c}$.

b consists of the composition of two transformations in the first step: it is a high level procedure for primary school children.

a is not so difficult but it involves the inversion of the direct transformations -31 and +14 into the symmetrical ones. This is not at all obvious for 9 or 10 year old children.

c does not require any composition or inversion of transformations. It is attempted (if not successfully) at a younger age, especially with small numbers.

$\mathrm{a}, \mathrm{b}$ and $\mathrm{c}$ do not represent the same 'relational calculus'. The properties taken into account, or the 'theorems in action' working at the 'signified level' are not the same.

All this can be summed up in the following schema. 
REALITY

SIGNIFIED

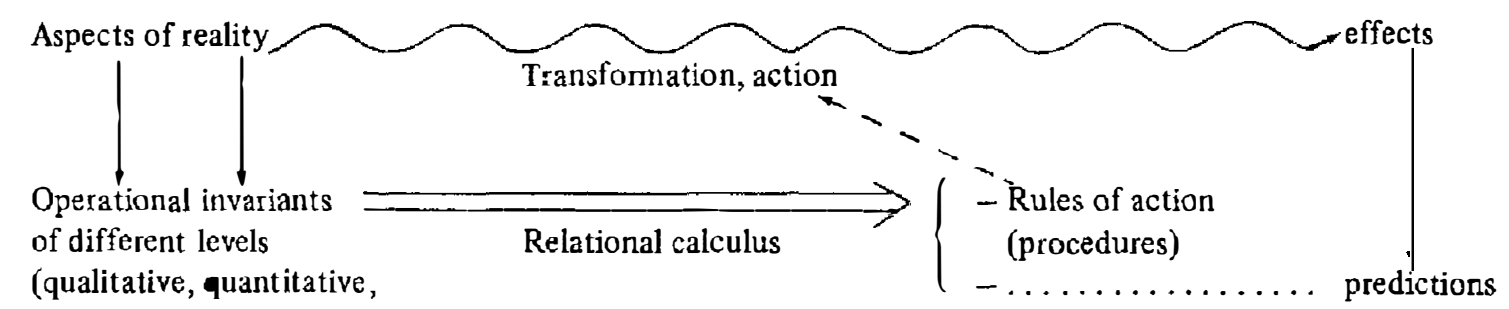

SIGNIFIER

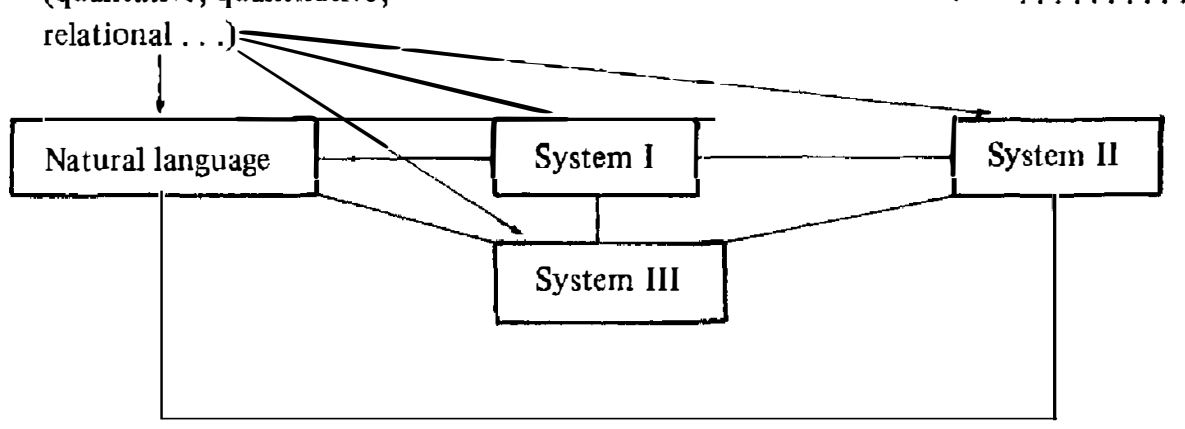


This schema is an oversimplification of the problems which I have tried to raise. It only traces the most important aspects and criteria of operational and symbolic thinking in building up both references of concepts with action in reality and handling of symbolic systems.

The first two levels illustrate the idea that operational concepts are built up through action and are tested against effectiveness of action and prediction in reality. The last two levels show the link between conceptualization and explicit symbolization and lay the stress on the plurality of symbolic systems and on the special part played by natural language.

Jean Piaget has done very important work on the building up of invariants through action. It seems to me that more work should now be carried out on relational invariants and on the use that children can make of symbolic systems. This work can hardly be done by pure psychological studies. It requires didactic studies for which both mathematicians and psychologists are needed.

CNRS, Paris

\section{R E F E R E N C E S}

Brousseau, G., Les obstacles épistémologiques et les problemes en mathématiques. La Problematique et l'enseignement de la mathematique. Some questions related to the use of problems in the teaching of mathematics. Commission Internationale pour l'Etude et l'Amélioration de l'Enseignement des Mathèmatiques. Louvain-la-Neuve, 1976, pp. 101-117.

Desjardins, M. and Hetu, J. C., L'activité mathématique dans l'enseignement des fractions. Presses Universitaires du Québec, 1974.

Hart, K., The Understanding of Fractions in the Secondary School. Acts of Second International Conference for the Psychology of Mathematics Education, Osnabrück, 1978, pp. 137-143.

Karplus, R., Karplus, E., .Fonnisano, M., and Paulsen, A., 'A Survey of proportional reasoning and control of variables in seven countries', Journal of Research in Science Teaching 14 (1977), 411-417.

Lunzer, E., Bell, A., and Shiu, C., Numbers and the World of Things: a Developmental Study. Shell Centre for Mathematics Education, University of Nottingham, 1976.

Nesher, P. and Katriel, T., 'A Semantic Analysis of Addition and Substraction Word Problems in Arithmetic', Educational Studies in Mathematics 8 (1977), 251-269.

Noelting, G., Constructivism as a Model for Cognitive Development and (Eventually) Learning. Acts of Second International Conference for the Psychology of Mathematics Education, Osnabrïck, 1978, pp. 205-224.

Rees, R., Mathematics in Further Education. Hutchinson Educational, 1973.

Shulman, M., Review of Recent Research Related to the Concepts of Fractions and Ratios. Acts of Second International Conference for the Psychology of Mathematics Education. Osnabrück, 1978. (Contains a good bibliography of English Literature.)

Skemp, R., The Psychology of Learning Mathematics, Pelican, 1971.

Vergnaud, G., 'Calcul relationnel et représentation calculable', Bulletin de Psychologie, 315 (1974-1975), 378-387. 
Vergnaud, G. and Durand, C., 'Structures additives et complexité psychogénétique', La Revue Française de Pédagogie 36, 1976, 28-43.

Vergnaud, G. and Ricco, G., Psychogenese et programmes d'enseignement: différents aspects de la notion de hièrarchie. Bulletin de Psychologie 330 (1976-77), 877-882.

Vergnaud, G., Ricco, G., Rouchier, A., Marthe, P. \& Metregiste, R., 'Quelle connaissance les enfants de sixieme ont-ils des "structures multiplicatives" élémentaires? Un sondage', Bulletin de l'APMEP 313 (1978), 323--357. 